\title{
PENGARUH JUMLAH PENDUDUK, JUMLAH PENGANGGURAN \\ DAN TINGKAT PENDIDIKAN TERHADAP PERTUMBUHAN EKONOMI DI WILAYAH GERBANG KERTOSUSILA
}

\author{
Alifah Yustina Salsabila \\ Email: Alifahyss@gmail.com \\ Program Studi Ekonomi Pembangunan Universitas Pembangunan Nasional Veteran” Jawa \\ Timur \\ Jl. Rungkut Madya No.1, Gn. Anyar. Surabaya \\ Niniek Imaningsih \\ Email: niniekimaningsih@gmail.com \\ Program Studi Ekonomi Pembangunan Universitas Pembangunan Nasional Veteran” Jawa \\ Timur \\ Jl. Rungkut Madya No.1, Gn. Anyar. Surabaya \\ Riko Setya Wijaya \\ Email: rikosetyawijaya.80@gmail.com \\ Program Studi Ekonomi Pembangunan Universitas Pembangunan Nasional Veteran” Jawa \\ Timur \\ Jl. Rungkut Madya No.1, Gn. Anyar. Surabaya
}

\begin{abstract}
ABSTRAK
Penelitian ini bertujuan untuk mengetahui dan menganalisis seberapa besar pengaruh jumlah penduduk, jumlah pengangguran dan tingkat pendidikan terhadap pertumbuhan ekonomi di wilayah Gerbang Kertosusila, yang nantinya dapat mengoptimalkan pertumbuhan ekonomi melalui peran pada masingmasing daerah. Penelitian ini kuantitatif yang menggunakan metode analisis regresi data panel dengan data cross section dan time series. Hasil penelitian menujukan bahwa jumlah penduduk memiliki pengaruh positif dan signifikan, lalu tingkat pendidikan tidak memiliki pengaruh secara signifikan dan pengangguran adalah variabel yang berpengaruh negatif dan signifikan terhadap pertumbuhan ekonomi, jumlah pengangguran yang tinggi berdampak pada penurunan ekonomi, yang kedepannya pemeintah harus memberi perhatian khusus agar perekonomian tidak semakin menurun.
\end{abstract}

Kata Kunci: Pertumbuhan Ekonomi, Jumlah Penduduk, Jumlah Pengangguran, Tingkat pendidikan Pertumbuhan Ekonomi

\begin{abstract}
This study aims to determine and analyze how much influence the population, the number of unemployed, and the level of education on economic growth in the Kertosusila Gate area, which will be able to optimize economic growth through the role of each region. This research is quantitative using the panel data regression analysis method. The results of the study show that the population has a positive and significant effect, then the level of education has no significant effect and unemployment is a variable that has a negative and significant effect on economic growth, a high unemployment rate has an impact on the economic decline, which in the future the government should pay special attention to the economy is not going down.
\end{abstract}

Keywords: Economic Growth, Population, Total Unemployment, Education Level Economic Growth 


\section{PENDAHULUAN}

Pertumbuhan ekonomi merupakan indikator penting untuk menjalani tahapan kemajuan selanjutnya, yaitu kesempatan kerja dan produktifitas serta distribusi pendapatan (Sitindaon, 2013). untuk mengetahui sejauh apa pertumbuhan ekonomi suatu daerah atau negara adalah dengan mengatahui tingkat Produk Domestik Regional Bruto (PDRB) rill, Dengan adanya pertumbuhan ekonomi rakyat dapat dikatakan sejahtera jika output perkapita mengalami peningkatan.

Pembangunan suatu negara tidak lepas dari pemerintah daerah yang memiliki peran penting dalam keberhasilkan perekonomian daerah yang ada melalui pemanfaatan sumber daya secara optimal. Sebagai upaya untuk meningkatkan peran serta kemampuan daerah tersebut dalam pembangunan maka pemerintah daerah tentunya dituntut untuk mandiri dalam pembiayaan kegiatan operasionalnya. Gerbangkertosusila sendiri merupakan Satuan Wilayah Pengembangan (SWP) sebagai pusat kegiatan perekonomian dari daerah - daerah lain di sekitarnya. Gerbang kertosusila merupakan singkatan atau akronim dari Kabupaten Gresik, Kabupaten Bangkalan, Kabupaten dan Kota Mojokerto, Kota Surabaya, Kabupaten Sidoarjo, dan Kabupaten Lamongan. Menurut Perda Provinsi Jawa Timur No.4/1996 mengenai RTRW Provinsi Jawa Timur dan PP No.47/1996 tentang RTRW Nasional, pembentukan memiliki tujuan untuk mewujudkan pemerataan pembangunan antar daerah

Berdasarkan penelitian yang telah dilakukan oleh Handayani, dkk. (2016) yang menunjukkan bahwa jumlah penduduk memiliki pengaruh yang positif dan signifikan terhadap pertumbuhan ekonomi yang mana pertambahan jumlah penduduk dapat mempercepat pertumbuhan ekonomi pula. Sehingga, penduduk dalam pembangunan ekonomi termasuk hal penting dikarenakan pertumbuhan ekonomi sendiri selalu berkaitan dengan jumlah penduduk

Berdasarkan data Badan Pusat Statistik (BPS) Jakarta, bahwa Produk Domestik Bruto (PDRB) setiap tahunnya di Gresik, Bangkalan, Mojokerto, Surabaya, Sidoarjo, Lamongan pada tahun 2015-2019 mengalami kenaikan. Hal tersebut tentunya disebabkan oleh beberapa faktor. Jika tidak dipertahakan atau mencari solusi mengenai apa saja tindakan yang dapat dilakukan sebagai upaya pencegahan agar tidak terjadinya penurunan PDRB di wilayah Gerbang Kertosusila. Pembangunan ekonomi daerah adalah proses pemerintah daerah dan masyarakat yang ada disana mengelola sumber daya yang ada dan mebuat kemitraan antara pemerintah daerah dan sektor swasta agar dapat menciptakan lapangan pekerjaan dan menarik perkembangan kegiatan ekonomi di wilayah tersebut (Arsyad, 2004). 
Kebijakan pembangunan ekonomi dilaksanakan untuk mencapai pertumbuhan ekonomi yang tinggi dengan mengelola potensi dan sumber daya yang ada bagi masing-masing daerah yang mana dapat meningkatkan Produk Domestik Regional Bruto (PDRB). Oleh karena itu diperlukanya peran dari semua kalangan untuk mencapai tujuan tersebut. Oleh karena itu penelitian ini bertujuan untuk mengetahui dan menganalisis seberapa besar pengaruh jumlah penduduk, jumlah pengangguran dan tingkat pendidikan terhadap pertumbuhan ekonomi di wilayah Gerbang Kertosusila. dikarenakan pertumbuhan ekonomi di Provinsi Jawa Timur tidak lepas dari peran kontribusi Produk Domestik Bruto (PDRB) kabupaten/kota di Provinsi Jawa Timur. Dan pertumbuhan ekonomi juga dipengaruhi oleh beberapa faktor seperti: Jumlah Penduduk, Jumlah Pengangguran dan Tingkat pendidikan di setiap daerah.

\section{METODE PENELITIAN}

Analisis data dalam penelitian ini adalah menggunakan data panel (pooled data) yaitu gabungan dari data runtut waktu (time series) dan data silang (cross section) Dalam mengestimasi model regresi data panel menurut Basuki (2016) dapat dilakukan melalui tiga pendekatan, antara lain : Model Common Effect, Model Fixed Effect, dan Model Random Effect. Dengan model persamaan yang digunakan yaitu :

Yit $=\beta_{0}+\beta_{1} X_{1}$ it $+\beta_{2} X_{2}$ it $+\beta_{3} X_{3}$ it $+\beta_{4} X_{4}$ it + eit

Ket:

$\mathrm{B} \quad=$ Koefisien intersip

$\mathrm{X}_{1} \quad=$ Jumlah Penduduk (Jiwa)

$\mathrm{X}_{2} \quad=$ Jumlah pengangguran (Jiwa)

$\mathrm{X}_{3} \quad=$ Tingkat Pendidikan (Persen)

i $\quad=$ Banyaknya observasi (Kabupaten/Kota) di Jawa Timur

$\mathrm{t} \quad=$ Waktu (Periode Tahun 2005-2019)

- Common Effect Model

Adalah pendekatan model data panel yang paling sederhana karena hanya mengombinasikan antara data runtut waktu (time series) dan data silang (cross section) Pada model ini tidak diperhatikan dimensi waktu maupun individunya, sehingga diasumsikan bahwa perilaku data daerah Gerbang Kertosusila sama dalam berbagai kurun waktu. 
- $\quad$ Fixed Effect Model

Model ini mengasumsikan bahwa perbedaan antar individu dapat diakomodasi dari perbedaan intersepnya. Untuk mengestimasi data panel model Fixed Effect menggunakan tehnik, untuk menangkap perbedaan intersep antar daerah. Model estimasi ini sering juga disebut dengan teknik least Squares Dummy Variable (LDSV).

- Random Effect Model

Model ini akan mengestimasi data panel dimana variable gangguan mungkin saling berhubungan antar waktu dan antar individu. Pada model random effect perbedaan intersep diakomodasi oleh error terms masing-masing daerah. Keuntungan menggunakan model ini yakni menghilangkan heteroskedastisitas. Model ini juga disebut dengan Error Component Model (ECM) atau teknik Generalized Least Squar (GLS)

- Uji Pemilihan Model

Terdapat beberapa pengujian yang dapat dilakukan untuk memilih model manakah yang paling tepat dalam mengelola data panel (Basuki, 2016) yaitu:

a. Uji Chow

Adalah pengujian untuk menentukan antara model fixed effect atau Common Effect yang paling tepat digunakan untuk mengestimasi data panel. Jika nilai $\mathrm{F}$ hitung lebih besar dari $\mathrm{F}$ kritis maka hipotesis nul ditolak dan model yang tepat untuk regresi data panel adalah menggunakan model Fixed Effect.

b. Uji Hausman

Adalah pengujian statistik untuk memilih apakah model Fixed Effect atau Random Effect yang paling tepat digunakan. Apabila nilai statistik Hausman lebih besar dari nilai kritis Chi-Squares maka model yang paling tepat untuk regresi data panel adalah model Fixed Effect.

- Uji Statistik

a. Uji Koefisien Determinasi (Adjusted)

Menurut Ghazali (2013), Koefisien determinasi untuk mengukur seberapa jauh kemampuan model dalam menerangkan variasi variable dari dependen. Nilai yang kecil berarti kemampuan variabel independen dalam menjelaskan variasi variabel dependen amat terbatas. Nilai yang mendekati satu berarti variabel independen 
memberikan hampir semua informasi yang di butuhkan untuk memprediksi variasi variabel dependen.

\section{b. Uji Simultan (Uji F)}

Menurut Ghazali (2013), uji F pada dasarnya bertujuan untuk menunjukkan apakah semua variabel bebas atau independen yang di masukkan dalam model mempunyai pengaruh secara bersama-sama terhadap variabel terikat atau dependen. Uji F ini dilakukan dengan menggunakan nilai signifikansi.

\section{c. Uji Parsial (Uji T)}

Menurut Ghazali (2013), uji T pada dasarnya bertujuan untuk menunjukkan seberapa jauh pengaruh satu variabel penjelas atau independen secara individual dalam menerangkan variabel dependen. Rumusan hipotesis yang digunakan sebagai berikut: $\mathrm{H}_{0}$ : variabel independen tidak berpengaruh signifikansi terhadap variabel dependen. Ha: variabel independen berpengaruh secara signifikan terhadap variabel dependen. Adapun kriteria pengujiannya sebagai berikut: Ho diterima jika tingkat signifikansi $>0,05$ Ha diterima jika tingkat signifikansi $<0,05$

\section{HASIL DAN PEMBAHASAN}

\section{HASIL}

A. Common Effect Model (CEM)

Tabel 1 Common Effect Model

\begin{tabular}{|lc|}
\hline \hline Variable & Coefficient \\
\hline \hline C & -12.44413 \\
LOGJPENDUDUK & 1.338741 \\
LOGJPENGANGGU & \\
RAN & -1.085585 \\
LOGTPENDIDIKAN & 2.778743 \\
\hline \hline R-squared & 0.826524 \\
\hline
\end{tabular}

Sumber: Data diolah dengan Eviews 10

Dari hasil regresi pada model common effect models didapatkan bahwa nilai koefisien pada Jpenduduk $=1.338741$, Jpengangguran $=-1.085585$, Tpendidikan $=2.778743$, Dengan R-squared sebesar 0.826524 


\section{B. Fixed Effect Model (FEM)}

Dari hasil regresi sebesar 0,0000 menunjukan bahwa pada model ini semua variabel signifikan yaitu jpenduduk, jpengangguran, tpendidikan karena prbabilitas F-statistik sebesar 0,0000. dan. R-squared menunjukkan hasil yaitu sebesar 0,993013.

C. Random Effect Model (REM)

Tabel 2 Random Effect Model

\begin{tabular}{|l|l|}
\hline$R$-squared & 0.703683 \\
\hline Adjusted $R$-squared & 0.694882 \\
\hline
\end{tabular}

Sumber: BPS statistik Data diolah dengan Eviews 10

Nilai Adjusted R-Squared sebesar 0.694882, yang berarti bahwa variasi dalam variabel independen dapat dijelaskan sebesar $69,48 \%$ dari variabel dependen.

D. Uji Chow

Tabel 3 Hasil Uji Chow

\begin{tabular}{|lcrr|}
\hline Effects Test & Statistic & d.f. & Prob. \\
\hline \hline Cross-section F & 17.820846 & $(6,95)$ & 0.0000 \\
Cross-section Chi-square & 79.172080 & 6 & 0.0000 \\
\hline
\end{tabular}

Sumber: BPS statistik Data diolah dengan Eviews 10

Dari regresi pengujian antara Commond Effects Model dan Fixed Effects Model didapatkan hasil probabilitas Cross-section Chi-square yaitu sebesar 0,0000. Sehingga probabilitas Cross-section Chi-square lebih kecil dari alfa $(0,0000<0,05)$. Maka H0 ditolak, artinya Fixed Effect Model merupakan model yang tepat

E. Uji Haussman

Tabel 4 Uji Haussman

\begin{tabular}{|lrrr|}
\hline Test Summary & $\begin{array}{r}\text { Chi-Sq. } \\
\text { Statistic }\end{array}$ & Chi-Sq. d.f. & Prob. \\
\hline \hline Cross-section random & 53.490529 & 3 & 0.0000 \\
\hline \hline
\end{tabular}

Sumber: BPS statistik Data diolah dengan Eviews 10

Berdasarkan Hasil Uji Hausman penelitian ini dengan menggunakan E-Views 10 diperoleh nilai probabilitas Chi-Square sebesar 0.0000 yang memiliki nilai lebih kecil dari 0.05 maka hasilnya adalah menolak H0. Dengan demikian kesimpulannya adalah 
bahwa Model Fixed Effect (FEM) lebih tepat digunakan dibandingkan dengan Model Random Effect (REM).

Uji Statistik

Tabel 8 hasil uji statistik

\begin{tabular}{lrccc}
\hline \hline \multicolumn{1}{c}{ Variable } & Coefficient & Std. Error & t-Statistic & Prob. \\
\hline \hline \multicolumn{1}{c}{ C } & -9.865545 & 5.830004 & -1.692202 & 0.0940 \\
LOGJPENDUDUK & 1.285836 & 0.382188 & 3.364411 & 0.0011 \\
LOGJPENGANGGU & & & & \\
$\quad$ RAN & -0.301207 & 0.151502 & -1.988141 & 0.0497 \\
LOGTPENDIDIKAN & 1.460961 & 0.898967 & 1.625156 & 0.1075 \\
$\quad$ AR(1) & 0.915827 & 0.036217 & 25.28693 & 0.0000 \\
\hline \hline R-squared & 0.965548 & Mean dependent var & 9.989060 \\
Adjusted R-squared & 0.964066 & S.D. dependent var & 1.574447 \\
S.E. of regression & 0.298457 & Akaike info criterion & 0.469290 \\
Sum squared resid & 8.284114 & Schwarz criterion & 0.601176 \\
Log likelihood & -17.99522 & Hannan-Quinn criter. & 0.522635 \\
F-statistic & 651.5962 & Durbin-Watson stat & 2.125980 \\
Prob(F-statistic) & 0.000000 & & & \\
\hline \hline & \multicolumn{4}{c}{} \\
Inverted AR Roots & .92 & & \\
\hline \hline
\end{tabular}

Sumber: BPS statistik Data diolah dengan Eviews 10

A. Koefisien Determinasi (Adjusted R2

Dapat diketahui bahwa variabel X1, X2, dan X3 secara bersama-sama memiliki sumbangan pengaruh terhadap Y sebesar 0,964 atau 96,4\% dan sisa dipengaruhi faktor lain yang tidak diteliti.

\section{B. Uji Simultan (Uji F)}

Nilai F tabel dapat dilihat pada tabel F statistik pada df 1 = jumlah variabel-1 atau 4-1 $=3$ dan df 2 = n-k-1 atau 105-3-1 = 101 ( $\mathrm{k}$ adalah jumlah variable independen). Dengan signifikansi 0,05 diperoleh hasil $\mathrm{F}$ table $=2,69$.

Variabel Jumlah Penduduk, Jumlah Pengangguran dan Tingkat pendidikan secara bersama-sama berpengaruh terhadap PDRB Hal ini karena nilai F hitung > F table (651.59> 2,69) atau signifikansi > 0,05 sehingga Ho diterima

\section{Uji Parsial (Uji T)}

Uji t dilakukan untuk mengetahui signifikasi atau tidaknya masing - masing variabel independen terhadap variabel dependen secara individu.

Dari hasil estimasi:

1.) Variabel $X 1$ (Jumlah Penduduk) 
Dari hasil estimasi didapatkan hasil besar probabilitas variabel X1 yaitu 0,0011. Sehingga probabilitas variabel X1 lebih kecil dari alfa $(0,0011<0,05)$ maka variabel X1 signifikan dan variabel X1 (Jumlah Penduduk) berpengaruh terhadap Y (Produk Domestik Regional Bruto).

2.) Variabel $X 2$ (Jumlah Pengangguran)

Dari hasil estimasi didapatkan hasil besar probabilitas variabel X2 yaitu 0,0497. Sehingga probabilitas variabel X2 lebih kecil dari alfa $(0,0497<0,05)$ maka variabel X2 signifikan dan variabel X2 (Jumlah Pengangguran) berpengaruh terhadap Y (Produk Domestik Regional Bruto.

3.) Variabel $X 3$ (Tingkat Pendidikan)

Dari hasil estimasi didapatkan hasil besar probabilitas variabel X3 yaitu 0,1075. Sehingga probabilitas variabel X3 lebih besar dari alfa $(0,0000>0,05)$ maka variabel X3 tidak signifikan dan variabel X3 (Tingkat Pendidikan) tidak berpengaruh terhadap Y Y (Produk Domestik Regional Bruto.

\section{PEMBAHASAN}

\section{Pengaruh Variabel Jumlah Penduduk Terhadap Pertumbuhan Ekonomi}

Terjadi korelasi positif antara jumlah penduduk (X1) dan pertumbuhan ekonomi (Y). Jumlah penduduk memiliki pengaruh yang secara signifikan terhadap pertumbuhan ekonomi pada taraf nyata lima persen.

Pernyataan ini memiliki kesesuaian dengan teori model Kremerian dalam Mankiw (2006) yang menyatakan bahwa kunci dalam memajukan kesejahteraan ekonomi adalah pertumbuhan populasi. Jika penduduk semakin banyak, maka akan semakin banyak para ilmuwan, penemu, ataupun ahli mesin yang akan memberikan kontribusinya pada suatu inovasi dan kemajuan teknologi.

\section{Pengaruh Jumlah Pengangguran (X2) terhadap Pertumbuhan Ekonomi (Y)}

Terjadi korelasi negatif antara Jumlah Pengangguran (X2) dan pertumbuhan ekonomi (Y). Jumlah pengangguran berpengaruh secara signifikan terhadap pertumbuhan ekonomi pada taraf nyata lima persen.

Dapat diketahui bahwa pengangguran adalah sebuah permasalahan yang tentunya dapat menghambat jalannya perekonomian. Sebab jika tingkat pengangguran tinggi, maka daya beli masyarakat akan turun, dan menyebabkan konsumsi juga akan menurun. Menurunnya konsumsi tersebut berakibat pada turunnya produksi, sehingga akan berdampak pada turunnya pertumbuhan ekonomi. Hasil penelitian ini sesuai dengan teori dari Keynesian yang 
mengatakan bahwa perekonomian akan menjadi stabil dan tumbuh dengan baik jika tidak adanya pengangguran Kondisi ini dilandaskan kekuatan pada mekanisme pasar yang akan selalu menuju keseimbangan.

\section{Tingkat Pendidikan (X3) terhadap Pertumbuhan Ekonomi (Y)}

Terjadi korelasi positif antara Tingkat Pendidikan (X2) dan pertumbuhan ekonomi (Y). Tingkat pendidikan tidak berpengaruh secara signifikan terhadap pertumbuhan ekonomi pada taraf nyata lima persen.

Hasil penelitian ini kesamaan dengan teori alokasi atau persaingan status yang dikemukakan pada tahun 70-an dan mendapat dukungan dari Lester Thurow (1974), John Meyer (1977) dan Randall Collins (1979) bahwa tingkat pendidikan tidak selalu sesuai dengan kualitas pekerjaannya, sehingga orang yang berpendidikan tinggi maupun yang rendah tidak berbeda produktivitasnya dalam menyelesaikan pekerjaan yang sama.

\section{KESIMPULAN \& SARAN}

Variabel jumlah penduduk mempunyai pengaruh positif dan signifikan terhadap pertumbuhan ekonomi maka jika jumlah penduduk suatu wilayah meningkat, maka akan diikuti oleh peningkatan pertumbuhan ekonomi di wilayah tersebut. Kondisi ini dikarenakan penduduk memiliki fungsi ganda dalam perekonomian, yaitu sebagai produsen dan konsumen. Maka penduduk merupakan faktor yang berpengaruh terhadap perekonomian, namun mereka harus memiliki potensi yang dapat menghasilkan tenaga kerja yang sudah siap kerja (skills labour). Sedangkan Variabel jumlah pengangguran mempunyai pengaruh negatif dan signifikan terhadap pertumbuhan ekonomi jika jumlah pengangguran mengalami peningkatan, maka akan diikuti oleh penurunan pertumbuhan ekonomi. Kondisi tersebut dikarena pengangguran adalah suatu masalah yang dapat menghambat jalannya perekonomian. Sebab jika pengangguran di suatu wilayahtinggi, maka daya beli masyarakat akan turun, dan menyebabkan konsumsi juga akan menurun. Penduduk merupakan faktor yang berpengaruh terhadap perekonomian. Dengan adanya jumlah penduduk yang banyak, maka perekonomian di suatu wilayah akan berkembang. Namun tentunya mereka harus memiliki potensi yang mampu menghasilkan tenaga kerja yang telah siap kerja (skills labour). Dan variabel tingkat pendidikan mempunyai pengaruh positif dan tidak signifikan terhadap pertumbuhan ekonomi maka tingkat pendidikan tidak selalu sesuai dengan kualitas pekerjaannya, sehingga orang yang memiliki pendidikan tinggi ataupun rendah tidak berbeda produktivitasnya dalam menangani suatu pekerjaan yang sama. Pelatihan yang dapat menbah skill perlu di adakan guna memberikan tambahan pengetahuan untuk tenaga kerja yang berpendidikan rendah. Hal 
tersebut diberikan agar masyarakat dapat mengikuti perkembangan teknologi dan semakin banyak pula masyarakat yang skillnya

\section{DAFTAR PUSTAKA}

Badan Pusat Statistik 2010. Produk Domestik Regional Bruto Kabupaten/Kota di Indonesia 2005-2009 diakses pada 15 Februari 2021 https://www.bps.go.id/publication.html

Badan Pusat Statistik 2014. Produk Domestik Regional Bruto Kabupaten/Kota di Indonesia 2009-2013 diakses pada 15 Februari 2021 https://www.bps.go.id/publication.html

Badan Pusat Statistik 2017. Produk Domestik Regional Bruto Kabupaten/Kota di Indonesia 2012-2016 diakses pada 15 Februari 2021 https://www.bps.go.id/publication.html

Badan Pusat Statistik 2020. Produk Domestik Regional Bruto Kabupaten/Kota di Indonesia 2015-2019 diakses pada 15 Februari 2021 https://www.bps.go.id/publication.html

Basuki, A. T. (2016). Pengantar Ekonometrika (Dilengkapi Penggunaan Eviews). Sleman (ID), Danisa Media.

Ghozali, I., \& Ratmono, D. (2013). Analisis multivariat dan ekonometrika: Teori, konsep, dan aplikasi dengan EVIEWS 10 (Edisi 2. Cetakan ke-2). Semarang: Badan Penerbit Universitas Diponegoro.

Handayani, N. S., Bendesa, I., \& Yuliarmi, N. (2016). Pengaruh Jumlah Penduduk, Angka Harapan Hidup, Rata-Rata Lama Sekolah, dan PDRB Per Kapita Terhadap Pertumbuhan Ekonomi di Provinsi Bali. Jurnal Ekonomi dan Bisnis Universitas Udayana, 5(10), 34493474.

Mankiw, N Gregory. 2007. "Makroekonomi,(Terjemahan)." Harvard University, Edisi Keenam, Erlangga, Jakarta.

Mankiw, N Gregory. 2006. “Teori Makroekonomi Edisi Keenam.” Jakarta: Erlangga.

Sitindaon, D. (2013). FAKTOR-FAKTOR YANG MEMPENGARUHI PERTUMBUHAN EKONOMI DI KABUPATEN DEMAK SKRIPSI Diajukan dalam rangka menyelesaikan studi strata satu Untuk mencapai gelar Sarjana Ekonomi (Doctoral dissertation, Universitas Negeri Semarang).

Todaro, Michael P. 2000. "Pembangunan Ekonomi Di Dunia Ketiga Edisi Ketujuh.” Jakarta: erlangga.

Widarjono, A. (2013). Ekonometrika pengantar dan aplikasinya disertai panduan Eviews. Yogyakarta: Upp Stim Ykpn.

Widayati, Heni Wahyu, Lorentino Togar Laut, and Rian Destiningsih. 2017. "Pengaruh Jumlah Tenaga Kerja, Tingkat Pendidikan Dan Jumlah Pengangguran Terhadap Pertumbuhan Ekonomi Kabupaten Magelang Tahun 1996-2017." DINAMIC : Directory Journal of Economic 1(2): 182-94. 